\title{
Relaps Refrakter Multiple Myelomda Daratumumabın Tekli ve Kombine Tedavi Sonuçları-Tek Merkez Deneyimi
}

\section{Results of Monotherapy and Combination Treatment of Daratumumab in Relapsed Refractory Multiple Myeloma - Single Center Experience}

\author{
Aydan Akdeniz ${ }^{1 *}$, Fatma Akbaş ${ }^{1}$, Anıl Tombak ${ }^{1}$ \\ ${ }^{1}$ Mersin Üniversitesi Tıp Fakültesi Onkoloji Hastanesi, Hematoloji Bilim Dalı, Mersin, Türkiye. \\ e-mail: akdenizdr@hotmail.com,drfatmaakbas@gmail.com, aniltombak@hotmail.com. \\ ORCID: 0000-0002-5160-4803 \\ ORCID: 0000-0002-4434-0010 \\ ORCID: 0000-0002-7195-1845 \\ *Sorumlu yazar/ Corresponding Author: Aydan Akdeniz \\ Gönderim Tarihi / Received: 25.02.2021 \\ Kabul Tarihi / Accepted: 23.05.2021 \\ DOI: $10.34087 /$ cbusbed. 886457
}

\begin{abstract}
Giriş ve Amaç: Son yıllarda multipl miyelom tedavi protokollerine proteazom inhibitörleri ve immünomodülatörlerin eklenmesiyle, yanıt oranları önemli ölçüde iyileşmiştir, ancak relaps refrakter hastalarda tedavi seçenekleri hala sınırlıdır ve sağkalım kısadır. Daratumumab, bir insan CD38 monoklonal antikorudur ve hem monoterapi ile hem de kombinasyon terapilerinde çok iyi bir yanıt elde etmiştir.

Klinik çalışmalarda etkinliği kanıtlanmış olmasına rağmen, daratumumabın gerçek yaşam verilerinden elde edilen literatür bilgileri ülkemizde oldukça sınırlıdır. Bu nedenle merkezimizde daratumumab ile tedavi edilen hastaların karakteristik özelliklerini ve yanıt oranlarını incelemeyi amaçladık.

Gereç ve Yöntemler: : Daratumumab ile tedavi edilen 10 hastanın dosyaları geriye dönük olarak incelendi. Demografik bilgileri ve yanıt oranlarını içeren veriler literatür ışığında geliştirildi.

Bulgular: Hastaların ortalama tanı yaşı 58 idi. Medyan takip süresi 58,3 ay ve medyan daratumumab tedavi süresi 3,9 ayd1. Medyan genel yanıt oranı \% 40 idi. En az kısmi yanıt alınan tüm hastalar dara-bor-dex kombinasyonu alıyordu. Hastaların toplam \% 60'1 hayattaydı. Daratumumabdan ölüme kadar geçen medyan süre 35 gündü.

Sonuç: Çalışmamızda relaps refrakter miyelom tedavisinde daratumumab ile literatür ile benzer şekilde olumlu yanıt oranları saptand1.
\end{abstract}

Anahtar kelimeler: Daratumumab, Multiple myelom, Sağkalım.

\section{Abstract}

Objective: With the addition of proteasome inhibitors and immunomodulators to multiple myeloma treatment protocols in recent years, the response rates have improved considerably, but in relaps refractory patients treatment options are still limited and survival is short. Daratumumab is a human CD38 monoclonal antibody and has achieved a very good response in both monotherapy and combination therapies.

Although it has been proven effective in clinical studies, the literature information of daratumumab obtained from real-life data, is very limited for our country. Therefore we aimed to examine the characteristics and response rates of patients who were treated with daratumumab in our center.

Materials and Methods: Files of 10 patients treated with daratumumab, were analyzed retrospectively. Data containing demographics and response rates were evoluated in the light of literature.

Results: Mean age at diagnosis of patients was 58 years. Median follow-up time was 58.3 months and median duration of daratumumab treatment was 3.9 months. The median overall response rate was $40 \%$. All patients with at least partial response were taking the Dara-Bor-Dex combination. Totally $60 \%$ of patients were alive. Median time from daratumumab to death was 35 days.

Conclusion: In our study, similar with the literature, response rates were improved with daratumumab in the treatment of relapsed refractory myeloma. 
Keywords: Daratumumab, Multiple myeloma, Survival.

\section{Giriş}

Multipl myelom (MM) monoklonal immunglobulin üreten plazma hücre proliferasyonu ile giden bir kemik iliği malignitesidir. İskelet sistemi tutulumu, böbrek fonksiyon bozukluğu, hiperkalsemi, B semptomları, total serum proteininde artış, idrar ve serum immunfiksasyon elektroforezinde monoklonalite ile karakterizedir. Son 20 yilda tedaviye proteazom inhibitörleri ve immunmodülatörler eklenmesi ile sağkalım oldukça iyileşmekle birlikte, [1] dirençli hasta grubunda halen tedavi yönetimi zor ve sağkalımlar oldukça kısadır.

CD38 özellikle MM hücrelerinde eksprese edildiğinden anti CD38 inhibitörleri kompleman ve antikor bağımlı sitotoksisite, fagositoz ve apopitoz mekanizmaları ile hücre ölümüne neden olarak, özellikle relaps refrakter hastalarda hedefe yönelik tedavi seçeneklerinden biri olmuştur. $[2,3]$ Daratumumab hem monoterapi hem de bortezomib ve lenalidomid ile kombine kullanımında oldukça iyi yanıt alınan CD38 inhibitörüdür.[4] Yakın zamanda subkutan uygulama onay alsa da şu an için önerilen kullanım șekli ilk 8 hafta boyunca $16 \mathrm{mg} / \mathrm{kg}$ haftada bir, sonraki 16 hafta boyunca aynı dozda haftada 2, daha sonra progresyona kadar her 4 haftada bir intravenöz uygulama şeklindendir [5]. Monoterapide genel yanıt oranı $\% 31.1$, median progresyonsuz sağkalım 20.1 ay iken [6] bortezomib-dexametazon ile kombinasyonunda (dara-bor-len) progresyonsuz sağkalımı 7.1 aydan 16.7 aya çıktığı [7], thalidomid ve bortezomib (dara-bor-tal) ile kombinasyonunda ise $\% 39$ hastada en az tam yanıt olduğu görülmüştür.[8] Pollux çalışmasında ise lenalidomide and dexamethasone kombinasyonuna dara eklendiğinde (dara-len-dex) 12 aylık progresyonsuz sağkalımın $\% 60.1$ 'den \%83.2'e, genel sağkalımın ise \%76.4 den \%92.9 kadar çıktığı görülmüştür. [9]

Türkiye'de daratumumab ile ilgili gerçek yaşam verilerini içeren literatür sayısı erken erişim programından elde edilen 42 hastalık bir monoterapi çalışması dışında oldukça kısıtlıdır [10] Bu nedenle biz de bu çalışmada merkezimizde hem monoterapi olarak, hem de kombinasyon ile daratumumab alan hastaların yanıtlarını ve sağkalımlarını değerlendirdik.

\section{Materyal ve Metot}

Mersin Üniversitesi hematoloji bölümünde multipl myelom tanisi ile daratumumab monoterapisi ve kombinasyon tedavisi alan toplam 10 hastanın dosyaları retrospektif olarak incelendi. Hastaların demografik verileri, daratumumab öncesi aldıkları tedaviler, daratumumab ile birlikte verilen tedavi ajanları, daratumumaba yanıtları ve yanıt süreleri, ölüm oranları ve nedenleri ile advers olaylar kaydedildi. En az parsiyel yanıt alan hastaların oranı genel yanıt oranı olarak ifade edildi. Sonuçlar literatür eşliğinde değerlendirildi

\section{Bulgular ve Tartışma \\ 3.1.Bulgular}

Hastaların ortalama tanı yaşı 58 , daratumumab başlama yaş1 62.9 idi. Toplam takip süreleri ortalama 58.3 ay idi. Hastaların \%30'u hafif zincir myelom, $\% 30$ 'u Ig G tipi myelom, \%40'1 ise Ig A tipi myelom idi. \%30'unda plazmositom mevcuttu, \%60'1 ISS evre3, \%20'si evre-2, \%20'si evre-1 idi. Daratumumabdan önce median 6 basamak tedavi almışlardı. Tanıdan daraya kadar ortalama geçen süre 53.2 aydı. Hastaların $\% 80$ i dara-bor-dex kombinasyou alırken, \%10 daralen-dex, $\% 10$ da daratumumab monoterapisi aldı. Dara öncesi kreatin yüksekliği olan 5 hastanın 1 inde kreatin değerinin düzeldiği görülürken, daratumumab öncesi kreatin yüksekliği olmayan 5 hastadan 2 tanesinde kreatin normal düzeyin üzerine çıkt, her iki hasta da eks oldu. Daratumumab öncesi ortalama hemoglobin değeri $8.47 \mathrm{gr} / \mathrm{dl}$ iken sonrasında $9.3 \mathrm{gr} / \mathrm{dl}$ ye çıktığı görüldü. Hastaların \%90'ında hemoglobinde daratumumab öncesine göre düzelme görülürken daratumumaba refrakter olan 1 hastada hemoglobin değerinin tedavi ile azaldığ görüldü. Daratumumab tedavi sonrası median genel yanıt oran $1 \% 40 \mathrm{iken} \mathrm{(} \% 10$ tam yanıt (complet remission-CR), \%20 çok iyi parsiyel yanıt (very good partial response-VGPR, $\% 10$ parsiyel yanıt (partial response-PR), $\% 30$ hastada stabil hastalık, \%20 hastada minimal yanit, \%10 hastada da progresif hastalık izlendi. Hastaların yanıt durumuna göre klinik karakteristikleri Tablo 1'de özetlenmiştir.

En az parsiyel yanıt alınan tüm hastalar dara-bor-dex kombinasyonu alıyordu. Hastaların \%60 1 hayatta idi. Eks olan 4 hastada ölüm nedenleri tümör lizis sendromu (2 hasta) ,sepsis ve multipl myelom dışı neden (Femur kırı operasyon sonras1 sepsis) idi. Hayatta kalan hastaların hepsi ISS evre-3 idi ve hepsi dara-bor-dex tedavisi alıyordu. Tümör lizis sendromu ile eks olan hastaların ikisinde de plazmositom mevcuttu. Daratumumabdan ölüme kadar median süre 35 gün idi. Daratumumaba yanıt alınan hastalarda median daratumumab tedavi süresi 5.1 ay idi. En az parsiyel yanıt alan hastaların daratumumab tedavisi halen devam etmektedir.

\subsection{Tartı̧̧ma}

Relaps refrakter myelom tedavisinde literatürde yüz güldürücü sonuçları olan daratumumab ile çalışmamızda da olumlu yanıtlar elde edildi. Beksaç ve arkadaşları tarafından yapılan, ülkemizde erken erişim programında olan 42 hastanın değerlendirildiği çalışmada genel yanıt oranını \%45.2 olup çalışmamızda bu oran \%40 idi.

Tablo 1. Hastaların yanıt durumlarına göre karşılaştırması 


\begin{tabular}{|l|c|c|c|}
\hline & $\begin{array}{l}\text { En az parsiyel yanıt } \\
\text { alın hastalar }\end{array}$ & $\begin{array}{l}\text { Yanıt alınamayan } \\
\text { hastalar }\end{array}$ & $\begin{array}{l}\text { Hastalıkla } \\
\text { eks olan hastalaskili }\end{array}$ \\
\hline Hasta sayısı (n) & 4 & 6 & 3 \\
\hline Hasta yaş1 (/ortalama) & 63,5 & 62,5 & 59 \\
\hline Hasta tanı yaş1 & 58,5 & 58,1 & 54,3 \\
\hline ISS evre 3 olan hasta oranı(\%) & 25 & 83,3 & 100 \\
\hline Ekstrameduller plazmositom oranı (\%) & 25 & 33 & 66 \\
\hline Dara kombinasyonu (\%) & Dara-Bor-Dex & $\begin{array}{l}\text { Dara-Bor-Dex (66) } \\
\text { Dara(16,6) } \\
\text { Dara-Len(16,6) }\end{array}$ & $\begin{array}{l}\text { Dara-Bor-Dex } \\
\text { Dara } \\
\text { Dara-Len }\end{array}$ \\
\hline Tanıdan daraya kadar geçen süre/ay & $(100)$ & 51,6 & 60,6 \\
\hline Daha öncealdı̆̆ tedavi sıra sayısı (median ) & 61,5 & 6 & 6 \\
\hline Median dara tedavi süresi (ay) & 6 & 66,6 & 1 \\
\hline Mortalite (\%) & 5.1 & & 100 \\
\hline
\end{tabular}

$\mathrm{Bu}$ fark hastalarımızın daha ileri evrede olmaları, daha ileri yaşta olmaları ve daratumumabın ileri basamaklarda kullanılmış olması ile açıklanabilir. Ayrıca tedavi süresi uzadıkça daha derin yanıtlar elde edildiği bilgisinden yola çıkarak takip süreleri arttıkça yanıt oranlarının da artacağı öngörülebilir. Her iki çalışmada hasta grubunun demografik ve klinik karakteristikleri Tablo 2'de karşılaştırmalı olarak değerlendirilmiştir.

Tablo 2. İki çalışmadaki hastaların karşılaştırmalı özellikleri

\begin{tabular}{|c|c|c|}
\hline & Mersin Üniversitesi & Beksaç ve ark. \\
\hline Hasta sayıs1 & 10 & 42 \\
\hline Hasta yaşı (/ortanca) & 62,9 & 56,5 \\
\hline ISS evre 3 olan hasta oran 1 & 60 & 51,4 \\
\hline En sık komorbidite (\% hasta) & $\begin{array}{l}\text { diabetes mellitus } \\
\text { kronik böbrek yetmezliği }\end{array}$ & $\begin{array}{l}\text { nöropati (12) } \\
\text { kronik böbrek yetmezliği (7) }\end{array}$ \\
\hline Median takip süresi (y1l) & 4,8 & 5,1 \\
\hline Median daratumumab tedavi süresi (ay) & 3,9 & 5,5 \\
\hline $\begin{array}{l}\text { Tanıdan daratumumaba kadar geçen süre } \\
\text { (ortalama) }\end{array}$ & 53,2 & 66.8 \\
\hline $\begin{array}{l}\text { Daratumumabdan ölüme kadar süre } \\
\text { (ortalama) }\end{array}$ & 37 gün & belirtilmemiş \\
\hline Genel yanit oranı (\%) & 40 & 45,2 \\
\hline $\begin{array}{l}\text { Daha önce aldığı tedavi sıra sayısı } \\
\text { (median ) }\end{array}$ & 6 & 5,5 \\
\hline Ekstrameduller plazmositom oranı (\%) & 30 & 26,2 \\
\hline Daratumumab monoterapisi (\%) & 10 & 100 \\
\hline Daratumumab kombinasyonu (\%) & $\begin{array}{l}\text { Dara-Bor-Dex (80) } \\
\text { Dara-Len-Dex (10) }\end{array}$ & 0 \\
\hline Advers olay & $\begin{array}{l}1 \text { hasta (karın ağrısı) } \\
1 \text { hastada tümör lizis sendromu }\end{array}$ & $\begin{array}{l}76 \text { advers olay (en s1k } \\
\text { trombositopeni) }\end{array}$ \\
\hline Mortalite $(\%)$ & 40 & 40 \\
\hline
\end{tabular}


Aynı çalışmada 76 advers olay görülürken çalışmamızda sadece 2 hastada advers olay görülmesi, advers olay kayıtlarının iyi tutulmadığ 1 kuşkusunu doğurmaktadır. Çalışmamızda sağkalım analizi yapmak için oldukça kısa takip süreleri mevcuttur. Ancak median 3.9 ay gibi kısa bir takip süresinde bile $\% 40$ genel yanıt oranı elde edilmesi, tedavi süresi arttıkça daratumumabın sağkalım üzerine oldukça olumlu etkilerinin olacağını öngördürebilir. Çalışmamızda steroidle beraber bortezomib veya lenalidomid gibi ajanlarla kombine edilen daratumumabin pomalidomid veya karfilzomib ile kombine edildiği tedavi protokolleri de mevcuttur. Mevcut protokollere daratumumab eklemekle sağkalımların anlamlı derecede arttığı gösterilmiş olup, kombinasyonların birbirlerine olan üstünlüklerinin araştırıldığı karşılaştırmalı bir çalışma bulunmamaktadır. [11-13]

Erken basamaklarda verilmesi ile daha iyi yanıtlar elde edildiği bilinen daratumumab kemik iliği nakline uygun yeni tanı MM hastalarında bor-len-dex kombinasyonu ile birinci basamak tedavi olarak verildiğinde 22.1 aylık takip süresinde ciddi tam yanıt oranının $\% 45.4$ ten $\% 62.6$ ya çıktığı, minimal kalıntı hastalık negatifliğinin \%20.4'ten \%51'e çıktığ1 görülmüştür. Ayrıca her iki kolda nakil sonrası nötrofil ve trombosit engrafman süresinin benzer olduğu görülmüştür.

\section{Sonuç}

Daratumumab erken basamaklarda yer almaya başladıkça yaşam sürelerinin uzayacağı, subkutan uygulamanın yaygınlaşması ile hastane yatışları azalacağı, hasta uyumunun da artacağı inancindayı.

Özellikler relaps refrakter hastalarda daratumumabın etkinlik ve güvenliliği bir çok çalışma ile gösterilmişse de, uzun takip süreleri ve geniş hasta popülasyonlarını içeren gerçek yaşam verileri, tedavi sonuçları hakkındaki bilgilerimizi daha da netleştirecektir.

\section{References}

1.Hahalis, G, Kourakli, A, Gerasimidou, I, Kalogeropoulos, A.P Sitafidis, G, Papageorgiou, U, et al. Cardiac mortality in \{beta thalassemia major: resting but not dobutamine stress echocardiography predicts mortality among initially cardiac disease-free patients in a prospective 12-year study. European Journal of Heart Failure, 2009,11(12), 1178-81.

2.Malavasi, F, Deaglio, S, Funaro, A, Ferrero, E, Horenstein, A.L, Ortolan, E, et al., Evolution and function of the ADP ribosyl cyclase/CD38 gene family in physiology and pathology, Physiology Reviews. 2008,88(3):841-86.

3.Dima, D, Dower, J, Comenzo, R.L, Varga, C, Evaluating Daratumumab in the Treatment of Multiple Myeloma: Safety, Efficacy and Place in Therapy, Cancer Managment Research, 2020, 12, 7891-903.

4.Lonial, S, Weiss, B.M, Usmani, S.Z, Singhal, S, Chari, A, Bahlis, N.J, et al., Daratumumab monotherapy in patients with treatmentrefractory multiple myeloma (SIRIUS): an open-label, randomised, phase 2 trial, Lancet, 2016, 387(10027), 1551-60.

5.Usmani, S.Z, Nahi, H, Mateos, M.V, van de Donk, N, Chari, A, Kaufman, J.L, et al., Subcutaneous delivery of daratumumab in relapsed or refractory multiple myeloma, Blood, 2019, 134(8), 668 77.

6.Usmani, S.Z, Weiss, B.M, Plesner. T, Bahlis. N.J, Belch. A, Lonial, $\mathrm{S}$, et al., Clinical efficacy of daratumumab monotherapy in patients with heavily pretreated relapsed or refractory multiple myeloma. Blood, 2016,128(1),37-44.

7.Mateos, M.V, Sonneveld, P, Hungria, V, Nooka, A.K, Estell, J.A, Barreto, W, et al., Daratumumab, Bortezomib, and Dexamethasone Versus Bortezomib and Dexamethasone in Patients With Previously Treated Multiple Myeloma: Three-year Follow-up of CASTOR, Clinical Lymphoma Myeloma Leukemia. 2020, 20(8), 509-18.

8.Moreau, P, Attal, M, Hulin, C, Arnulf, B, Belhadj, K, Benboubker, $\mathrm{L}$, et al., Bortezomib, thalidomide, and dexamethasone with or without daratumumab before and after autologous stem-cell transplantation for newly diagnosed multiple myeloma (CASSIOPEIA): a randomised, open-label, phase 3 study, Lancet, 2019, 394(10192), 29-38.

9.Dimopoulos, M.A, Oriol, A, Nahi,, H, San-Miguel J, Bahlis, N.J, Usmani, S.Z, et al., Daratumumab, Lenalidomide, and Dexamethasone for Multiple Myeloma, New England Journal of Medicine. 2016, 375(14), 1319-31.

10. Beksac, M, Aydin, Y, Goker, H, Turgut, M, Besisik, S.K, Cagirgan, $\mathrm{S}$, et al., Early Access Program Results From Turkey and a Literature Review on Daratumumab Monotherapy Among Heavily Pretreated Patients With Relapsed/Refractory Myeloma, Clinical Lymphoma Myeloma Leukemia, 2020, 20(8), e474-e84.

11. Siegel, D.S, Schiller, G.J, Samaras, C, Sebag, M, Berdeja, J, Ganguly, S, et al., Pomalidomide, dexamethasone, and daratumumab in relapsed refractory multiple myeloma after lenalidomide treatment, Leukemia, 2020, 34(12), 3286-97.

12. Dimopoulos, M, Quach, H, Mateos, M.V, Landgren, O, Leleu, X, Siegel, D, et al., Carfilzomib, dexamethasone, and daratumumab versus carfilzomib and dexamethasone for patients with relapsed or refractory multiple myeloma (CANDOR): results from a randomised, multicentre, open-label, phase 3 study, Lancet, 2020, 396(10245), 186-97.

13. Stege, C.A.M, Nasserinejad, K, Levin, M-D, Thielen, N, Klein, S.K, Ludwig, I, et al., Efficacy and Tolerability of Ixazomib, Daratumumab and Low Dose Dexamethasone (IDd) in Unfit and Frail Newly Diagnosed Multiple Myeloma (NDMM) Patients; First Interim Safety Analysis of the Phase II HOVON 143 Study, Blood, 2018, 132(Supplement 1), 596

http://edergi.cbu.edu.tr/ojs/index.php/cbusbed isimli yazarın CBU-SBED başlıklı eseri bu Creative Commons Alıntı-Gayriticari4.0 Uluslararası Lisansı ile lisanslanmıștır.

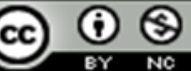

